\title{
Macronutrient intake and discrepancy with nutritional recommendations in a group of elderly diabetic subjects
}

\author{
Catherine Helmer ${ }^{1,2}$, Hélène Bricout ${ }^{1,2}$, Henri Gin $^{3}$ and Pascale Barberger-Gateau ${ }^{1,2}$ \\ ${ }^{1}$ INSERM, U593, 146 rue Léo Saignat, 33076 Bordeaux Cedex, France \\ ${ }^{2}$ Université Victor Segalen Bordeaux 2, 146 rue Léo Saignat, 33076 Bordeaux Cedex, France \\ ${ }^{3}$ CHU de Bordeaux, Hôpital du Haut-Lévêque, Service de nutrition-diabétologie, 1 avenue Magellan, Pessac, F-33 604, France
}

(Received 2 October 2006 - Revised 3 July 2007 - Accepted 9 July 2007)

Diet is a major aspect of glycaemic control in type 2 diabetes, particularly among the elderly. The objective of this study was to describe the food habits of elderly diabetic subjects compared with non-diabetic ones and to examine the difference between their nutritional behaviour and nutritional recommendations. This study was based on the Three City (3C) community-based cohort. The food habits of 1336 participants aged 65 or over, including 149 diabetic subjects, were evaluated using a FFQ and a $24 \mathrm{~h}$ recall of food consumption. For both sexes, intake of carbohydrates was lower for diabetic compared to non-diabetic subjects, essentially due to a lower intake of mono-/disaccharides. For diabetic men, this was compensated for by a higher intake of protein whereas women had a lower energy intake overall. Fibre intake was also higher in diabetic men. There was no absolute increase in fats intake, neither for men nor for women, and distribution of subtypes of fats (saturated, monounsaturated and polyunsaturated) did not differ between diabetic and non-diabetic subjects. Carbohydrates provided $40.5 \%$ of energy intake in diabetic men and $43.9 \%$ in diabetic women. Contrary to nutritional recommendations for diabetic subjects, for approximately two-thirds of the diabetic subjects carbohydrates represented less than $45 \%$ of daily energy intake. Although food habits of elderly diabetic subjects differed from those of non-diabetic ones, these habits are not totally in line with nutritional recommendations. These results should be taken into account to adapt nutritional advice given to the diabetic population.

Type 2 diabetes: Diet: Elderly: Epidemiology

Type 2 diabetes is a highly prevalent disease among the elderly ${ }^{1-4}$ and the incidence of clinical diabetic complications in this population has been associated with glycae$\mathrm{mia}^{5}$. Although the impact of diabetes control is less well known in the elderly population, it can be postulated that, like younger subjects, older diabetics could benefit from efficient control of their diabetes. Diet is the cornerstone of diabetes management. In type 2 diabetes, diet without additional anti-diabetic durgs is recommended as long as patients are meeting treatment goals, that is to say an glycosylated hemoglobin A1c (HbA1c) inferior to $7 \%^{6}$. In a recent study in the UK, approximately one-third of patients with type 2 diabetes were managed by diet alone ${ }^{7}$. This proportion could be even greater in the elderly population.

One of the objectives of diet is to assure an adequate ratio between carbohydrates and lipids, which contributes to improve insulin sensitivity, a major factor in type 2 diabetes care. Diet also has to ensure an adequate and sufficient energy intake, which is of paramount importance in elderly people. Even when anti-diabetic drugs are required, diet is still a major contributor to glycaemic control. Thus, analysis of diet among elderly diabetic subjects is of particular interest since increasing our knowledge of the nutritional behaviour of the elderly diabetic population should make it possible to adapt the nutritional advice given to this population.

Some studies have evaluated to what extent diabetic persons in the population follow dietary recommendations ${ }^{8-13}$. However, although most studies considered both insulin-dependent and non-insulin-dependent diabetes ${ }^{8,9,11-13}$, very few focused on the elderly population ${ }^{11,12}$ and study samples were often quite small. Moreover, to our knowledge, previous studies have compared the diets of diabetic subjects with those of non-diabetic subjects. However, only one previous study has investigated the discrepancy between diet and nutritional recommendations in diabetics ${ }^{12}$.

We hypothesised that diet of elderly diabetic subjects differs from that of non-diabetic ones but is not totally in line with nutritional recommendations for diabetic subjects. To test this hypothesis, we compared nutritional behaviours of diabetic subjects, first with non-diabetic subjects and then with nutritional recommendations for diabetics within the Three City (3C) Study, a French population-based cohort study of subjects aged 65 years and over designed to study the main vascular and neurodegenerative pathologies related to ageing. 


\section{Materials and methods}

\section{Design of the study}

The present study was part of the 3C Study, a collaborative research programme based on a longitudinal cohort of 9294 subjects aged 65 years and over. The main objective of this cohort is to estimate the risk of dementia and cognitive impairment attributable to vascular factors and to define target groups for future preventive strategies ${ }^{14}$.

Participants were recruited between March 1999 and March 2001 in three French cities: Bordeaux (2104 participants included), Dijon (4931) and Montpellier (2259). Details of the $3 \mathrm{C}$ Study are reported elsewhere ${ }^{14}$. To be eligible, people had: (1) to be aged 65 years or over, (2) to be living in one of the selected districts of the three cities and registered on the electoral rolls, and (3) not to be institutionalised. The study protocol was approved by the Ethical Committee of the Kremlin-Bicêtre University Hospital. Data collection included measurements and examinations common to the three centres, principally related to the central objective of the 3C Study. Additional data have been collected for centre-specific ancillary studies.

\section{Population}

The present paper is based on the data of the Bordeaux centre collected at the 2-year follow-up of the cohort. At this time, the Bordeaux centre had planned specific dietary objectives and had collected additional data on nutritional habits. Among the 2104 subjects initially included in the Bordeaux centre, $1761(83.7 \%)$ were visited in 2001-2. A total of 1661 $(94.3 \%)$ of them had a nutritional evaluation during this follow-up. After exclusion of three subjects with extremely low energy intake (less than $2092 \mathrm{~kJ}(500 \mathrm{kcal})$ ) on the $24 \mathrm{~h}$ recall, 1658 subjects were included in the present study.

\section{Data collection}

Data were collected during a face-to-face interview using a standardised questionnaire administered by trained psychologists. Data collection included sociodemographic variables, habits, personal medical history, current symptoms and diseases including diabetes, an inventory of all drugs used daily or regularly during the preceding month and anthropometric data (including height and weight). A fasting blood sampling, including fasting glucose level, was performed at the inclusion of the cohort but not repeated at this followup. Dietary information was collected by a specifically trained dietitian who administered a FFQ and a $24 \mathrm{~h}$ dietary recall. The FFQ was adapted from the questionnaire used for inclusion in the SU.VI.MAX (SUpplémentation en VItamines et Mineraux AntioXydants) randomised controlled study ${ }^{15}$. The FFQ asked for the usual frequency of consumption of broad categories of food and beverages at each meal and in intervals. During the $24 \mathrm{~h}$ recall, the dietitian registered all the meals and beverages consumed at any time during the previous day. Portion sizes were estimated by a picture booklet ${ }^{16}$ edited for the SU.VI.MAX study ${ }^{15}$. Then estimation of the daily nutrient intake of each participant was obtained

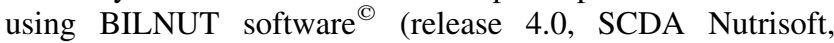
Cerelles, France) which includes food composition tables for
France ${ }^{17}$. At the end of the interview, the dietitian evaluated the reliability of the information provided by the subject based on the global coherence of the record and the cognitive abilities of the respondent. We excluded subjects for whom the report was judged as unreliable. For the same reason, we excluded demented participants from the sample. The validity of dietary questionnaires has been previously assessed by evaluating the association between total fat intake estimated from the $24 \mathrm{~h}$ recall and TAG assessed at baseline ${ }^{18}$. In addition, fish consumption frequency evaluated by the FFQ was also linked to the estimated EPA and DHA intake ${ }^{18}$.

\section{Diabetes diagnostic procedure}

The presence of diabetes was evaluated on a self-reported diagnosis of diabetes and/or a consumption of insulin or oral hypoglycaemic agents. In order to ensure that the non-diabetic group did not include any diabetic subjects, results of the fasting glucose level obtained at the baseline phase of the cohort were also taken into account. Thus, subjects who did not report diabetes but were classified as hyperglycaemic (fasting glucose level between $6 \cdot 1$ (included) and 7 (excluded) mmol/l) or diabetic (fasting glucose level equal or over $7 \mathrm{mmol} / \mathrm{l}$ ) on the blood sample at baseline were excluded ${ }^{19}$; in addition, subjects who did not report diabetes and had no blood sample at baseline were also excluded.

\section{Other variables}

Age, sex, marital status (married or living together, widowed, never married, and divorced or separated) and living conditions (alone or not) were considered. Educational level was evaluated on two levels, at least primary school level validated by a diploma, versus no diploma (low level). BMI was calculated (weight $/ \mathrm{size}^{2}$ ) in $\mathrm{kg} / \mathrm{m}^{2}$.

\section{Data analysis}

The Statistical Analysis Systems statistical software package version 8.2 (SAS Institute, Cary, NC, USA) was used. Student's $t$ test (for quantitative data) and $\chi^{2}$ test (for qualitative data) were used to compare socio-demographic characteristics and food consumption by groups. Nutrient intake has been presented in absolute values and nutrient densities for diabetic and non-diabetic subjects. Because of differences in diet between men and women, at least in total energy intake, most of the results are presented separately for men and women.

To compare nutrient intake between diabetic and nondiabetic subjects, linear regression models adjusted for age and educational level have been performed. Because of a significant interaction between gender and nutrient intake, these models have been performed separately for each sex. Statistical assumptions for these models have been verified graphically.

To evaluate the discrepancy between nutritional behaviours and nutritional recommendations in diabetic subjects, indicators of consumption were created for the three nutrient densities (carbohydrates, fats and protein), saturated fats and cholesterol. In France, nutritional recommendations for diabetic subjects in 2000 mention that consumption of 
carbohydrates should be between 45 and $50 \%$ of total energy intake, total fats between 25 and $35 \%$ and protein between 10 and $20 \%^{20}$. As data in the 3C Study were collected in 20012 , we chose to refer to these recommendations rather than more recent ones. At first, only consumption of carbohydrates was considered. Then, consumption of less than $300 \mathrm{mg}$ cholesterol and less than $10 \%$ of daily energy intake was also evaluated. As French recommendations differed slightly from American and European recommendations ${ }^{21,22}$, we also evaluated the proportion of subjects for whom consumption was not in compliance with those recommendations which advise more than $60 \%$ of daily energy intake as carbohydrates and monounsaturated fats.

\section{Results}

The initial sample consisted of 1658 subjects who underwent nutritional evaluation at the 2-year follow-up of our cohort. Among them, we excluded 107 subjects for whom dietary information was judged to be unreliable, due to a diagnosis of dementia ( $n 75)$, or based on the judgement of the dietitian (n 32). In order to avoid misclassification, we excluded 195 subjects who declared they were non-diabetic at this followup: 140 of them because they did not provide a blood sample at the baseline examination and fifty-five who had nevertheless hyperglycaemia in their blood sample at baseline. Finally, twenty subjects who were diagnosed as diabetic at the baseline phase of the study but who did not report diabetes at this follow-up were also excluded. Our final working sample therefore consisted of 149 diabetic participants and 1187 non-diabetic participants.

Characteristics of the diabetic and the non-diabetic sample according to gender are described in Table 1. Diabetic subjects were more often men $(54.4 \%$ of men among diabetics compared to $35.9 \%$ among non-diabetics, $P<0.0001$ ), but did not differ by age (76.0 years for diabetics and 75.9 for non-diabetics, $P=0.73$ ). Diabetic women had a lower level of education than non-diabetic women. As expected, BMI was greater among diabetic than non-diabetic subjects, especially for women, with a BMI 3.9 higher for diabetic women than for non-diabetic ones $(P<0 \cdot 0001)$.

\section{Food consumption}

Six non-diabetic subjects did not answer the FFQ and the results for food consumption are thus based on 1330 subjects. The number of meals per day, including snacks, was lower for diabetic women compared to non-diabetic women, whereas no difference was observed in men (Table 2). Only two diabetic subjects declared having only two main meals instead of three (breakfast, lunch and dinner). In men, fruit consumption per week was slightly more frequent among diabetic than among non-diabetic subjects as well as meat consumption. However, in women, no differences in consumption of fruit, vegetable, meat, pork-meat and fish were observed between diabetic and non-diabetics. On average, $87.3 \%$ of the diabetic subjects ate at least one piece of fruit a day and diabetic subjects ate about three vegetables a day. Non-diabetic subjects ate sweet foods more often than diabetic subjects, particularly for breakfast and also as snacks between meals for men. About $36 \%$ of non-diabetic subjects reported nibbling sweets between meals regularly (i.e. at least five times a week), compared to $21.5 \%$ of diabetic subjects $(P<0.0003)$. The use of artificial sweeteners was more frequent for diabetic subjects with more than half of them $(51.0 \%)$ adding an artificial sweetener to their drink regularly at breakfast, compared to $13.0 \%$ of the non-diabetic subjects.

Table 1. Principal characteristics according to sex and the diagnosis of diabetes, Three City Study, 2001-3

\begin{tabular}{|c|c|c|c|c|}
\hline & \multicolumn{2}{|c|}{ Men } & \multicolumn{2}{|c|}{ Women } \\
\hline & Diabetics ( $n$ 81) & Non-diabetics ( $n$ 426) & Diabetics (n 68) & Non-diabetics ( $n$ 761) \\
\hline \multicolumn{5}{|l|}{ Age (years) } \\
\hline Mean & $75 \cdot 1$ & $75 \cdot 5$ & $77 \cdot 1$ & $76 \cdot 2$ \\
\hline SD & $5 \cdot 0$ & 4.7 & $5 \cdot 0$ & $5 \cdot 0$ \\
\hline Range & $68 \cdot 3-88 \cdot 4$ & $68 \cdot 0-90 \cdot 0$ & $69 \cdot 3-94 \cdot 9$ & $67 \cdot 7-93.5$ \\
\hline Education (\% low) & $7 \cdot 4$ & $5 \cdot 4$ & $23 \cdot 9^{* * *}$ & $9 \cdot 3$ \\
\hline Living alone (\%) & $17 \cdot 3$ & $17 \cdot 4$ & $58 \cdot 8$ & $54 \cdot 4$ \\
\hline \multicolumn{5}{|l|}{ Marital status (\%) } \\
\hline Married/together & $77 \cdot 8$ & $78 \cdot 6$ & $33 \cdot 8$ & $40 \cdot 5$ \\
\hline Widowed & $11 \cdot 1$ & $14 \cdot 6$ & $51 \cdot 5$ & $39 \cdot 8$ \\
\hline Never married & $6 \cdot 2$ & $2 \cdot 1$ & $5 \cdot 9$ & $9 \cdot 6$ \\
\hline Divorced/separated & 4.9 & $4 \cdot 7$ & $8 \cdot 8$ & $10 \cdot 1$ \\
\hline \multicolumn{5}{|l|}{ BMI $(\%)$} \\
\hline$<21$ & 0.0 & $3 \cdot 8$ & $3 \cdot 2^{* \star *} \dagger$ & $10 \cdot 7$ \\
\hline $21-27$ & $49 \cdot 4$ & $54 \cdot 2$ & $28 \cdot 6$ & $54 \cdot 6$ \\
\hline $27-30$ & $29 \cdot 6$ & $27 \cdot 2$ & $25 \cdot 4$ & $18 \cdot 7$ \\
\hline$\geqq 30$ & $21 \cdot 0$ & $14 \cdot 8$ & $42 \cdot 9$ & $15 \cdot 9$ \\
\hline \multicolumn{5}{|l|}{$\mathrm{BMI}$} \\
\hline Mean & $27 \cdot 6^{\star}$ & $26 \cdot 7$ & $29 \cdot 8^{\star \star \star}$ & $25 \cdot 9$ \\
\hline SD & 3.4 & 3.5 & $5 \cdot 0$ & 4.3 \\
\hline
\end{tabular}

Values were significantly different from those of the non-diabetic subjects for each sex (Student's $t$ test for quantitative variables and $\chi^{2}$ test for qualitative variables): ${ }^{\star} P<0.05 ;{ }^{\star \star \star} P<0.001$.

† Global $P$ value for the BMI categories. 
Table 2. Food frequency consumption according to sex and the diagnosis of diabetes, Three City Study, 2001-3

\begin{tabular}{|c|c|c|c|c|c|c|c|c|}
\hline & \multicolumn{4}{|c|}{ Men } & \multicolumn{4}{|c|}{ Women } \\
\hline & \multicolumn{2}{|c|}{ Diabetics ( $n 81)$} & \multicolumn{2}{|c|}{ Non-diabetics ( $n$ 423) } & \multicolumn{2}{|c|}{ Diabetics ( $n$ 68) } & \multicolumn{2}{|c|}{ Non-diabetics ( $n 758)$} \\
\hline No. of meals per day & $4 \cdot 0$ & $1 \cdot 1$ & $4 \cdot 0$ & $1 \cdot 1$ & $4 \cdot 0^{*}$ & 1.0 & $4 \cdot 3$ & $1 \cdot 1$ \\
\hline $\begin{array}{l}\text { Fruit consumption per week } \\
\text { (excluding fruit juice) }\end{array}$ & $12 \cdot 9^{\star}$ & $5 \cdot 0$ & $11 \cdot 2$ & $5 \cdot 8$ & $12 \cdot 5$ & $6 \cdot 0$ & $11 \cdot 7$ & $5 \cdot 8$ \\
\hline Meat meals per week & $7 \cdot 6^{\star * *}$ & 2.5 & $6 \cdot 7$ & $2 \cdot 6$ & $6 \cdot 8$ & $2 \cdot 7$ & $6 \cdot 2$ & 2.5 \\
\hline Pork-meat meals per week & $2 \cdot 6$ & 3.0 & $2 \cdot 4$ & $2 \cdot 7$ & 1.6 & 1.9 & $1 \cdot 2$ & $1 \cdot 8$ \\
\hline Fish meals per week & 2.5 & $1 \cdot 8$ & $2 \cdot 3$ & 1.4 & $2 \cdot 0$ & 1.6 & $2 \cdot 3$ & 1.4 \\
\hline Sweets for breakfast per week & $8 \cdot 7^{\star \star *}$ & $5 \cdot 1$ & 3.5 & $5 \cdot 5$ & $7 \cdot 6^{\star * *}$ & $5 \cdot 0$ & $2 \cdot 2$ & $3 \cdot 2$ \\
\hline Snacking on sweets per week & $2 \cdot 2^{*}$ & 4.6 & 3.7 & $5 \cdot 0$ & $3 \cdot 1$ & $6 \cdot 1$ & $4 \cdot 5$ & $5 \cdot 9$ \\
\hline
\end{tabular}

Mean values were significantly different from those of the non-diabetic subjects for each sex (Student's $t$ test): ${ }^{\star} P<0.05 ;{ }^{\star \star \star} P<0.001$.

\section{Energy and nutrient intake}

Table 3 shows the absolute values of nutrient intake, assessed with the $24 \mathrm{~h}$ recall, for both sexes according to diabetic status. Comparisons between diabetic and non-diabetic subjects have been performed using linear regression models, separately for each sex. Adjusted for age and educational level, energy intake the day before significantly differed between diabetic and non-diabetic subjects only for women, with a lower energy intake for diabetic women.

Compared to non-diabetic men, diabetic men had a lower intake of carbohydrates, essentially due to a lower intake of mono- and disaccharides, and a higher intake of protein (Table 3). Fibre intake was also higher in diabetic men. As for men, intake of carbohydrates was also lower for diabetic women, but not accompanied by an increase in another nutrient, with thus a lower energy intake overall. The lower intake of carbohydrates in diabetic women was essentially due to a lower intake of mono- and disaccharides. Regarding intake of polysaccharides, there was no significant difference between diabetics and non-diabetics, neither for women nor for men. Alcohol intake was also lower in diabetic women.
Similarly, the comparison of nutrient densities evidenced a lower carbohydrate intake for diabetic subjects, and notably a lower mono- and disaccharide intake whatever the sex (Table 4). This reduction in carbohydrate intake was done simultaneously with a slightly higher intake of protein and fats. However, distribution of subtypes of fats (saturated, monounsaturated and polyunsaturated) was similar for diabetic and non-diabetic subjects for both sexes.

\section{Comparison with nutritional recommendations}

Proportions for nutrient densities for diabetic men and women are displayed in Table 4 . About $84 \%$ of the diabetic subjects did not consume between 45 and $50 \%$ of their daily energy intake as carbohydrates as recommended, with about twothirds $(63.8 \%)$ consuming less than $45 \%$. Even with less restrictive criteria, $43.0 \%$ of our diabetic subjects consumed less than $40 \%$ of their daily energy intake as carbohydrates. In addition, although $61.1 \%$ of the diabetic subjects consumed less than $300 \mathrm{mg}$ cholesterol, only $20.8 \%$ consumed less than $10 \%$ of daily energy intake as saturated fats. When all the

Table 3. Nutrient intake in absolute values assessed with the $24 \mathrm{~h}$ recall among diabetic and non-diabetic subjects according to sex, Three City Study, 2001-3

\begin{tabular}{|c|c|c|c|c|c|c|c|c|}
\hline & \multicolumn{4}{|c|}{ Men } & \multicolumn{4}{|c|}{ Women } \\
\hline & \multicolumn{2}{|c|}{ Diabetics ( $n$ 81) } & \multicolumn{2}{|c|}{ Non-diabetics ( $n$ 426) } & \multicolumn{2}{|c|}{ Diabetics ( $n 68)$} & \multicolumn{2}{|c|}{ Non-diabetics ( $n 761)$} \\
\hline & Mean & SD & Mean & SD & Mean & SD & Mean & SD \\
\hline Total energy (kJ) & $8294 \cdot 1$ & $2219 \cdot 2$ & $8603 \cdot 7$ & $2260 \cdot 7$ & $5715 \cdot 1^{\star *}$ & $1622 \cdot 7$ & $6465 \cdot 2$ & $1941 \cdot 3$ \\
\hline Carbohydrates (g) & $198 \cdot 8^{\star \star \star}$ & $64 \cdot 1$ & $233 \cdot 1$ & 76.5 & $149 \cdot 4^{\star \star \star}$ & $58 \cdot 7$ & $180 \cdot 7$ & $62 \cdot 2$ \\
\hline Mono-/disaccharides (g) & $76 \cdot 1^{\star \star \star}$ & $36 \cdot 5$ & $101 \cdot 8$ & $46 \cdot 0$ & $65 \cdot 7^{\star \star \star}$ & $35 \cdot 8$ & $87 \cdot 2$ & $35 \cdot 5$ \\
\hline Polysaccharides (g) & $122 \cdot 7$ & $49 \cdot 4$ & $131 \cdot 3$ & $51 \cdot 7$ & $83 \cdot 7$ & $35 \cdot 6$ & 93.5 & 43.9 \\
\hline Protein (g) & $94 \cdot 1^{\star \star}$ & 31.9 & $85 \cdot 2$ & $25 \cdot 6$ & 69.5 & $26 \cdot 6$ & $69 \cdot 8$ & 24.9 \\
\hline Total fats $(\mathrm{g})$ & 74.9 & $33 \cdot 3$ & $70 \cdot 0$ & $29 \cdot 8$ & $51 \cdot 3$ & 21.9 & 54.5 & $25 \cdot 1$ \\
\hline Saturated (g) & $32 \cdot 0$ & $16 \cdot 0$ & $29 \cdot 8$ & $13 \cdot 8$ & $22 \cdot 2$ & $10 \cdot 8$ & $23 \cdot 3$ & $12 \cdot 0$ \\
\hline Monounsaturated (g) & $27 \cdot 0$ & $12 \cdot 6$ & $25 \cdot 3$ & $12 \cdot 5$ & $17 \cdot 8$ & $8 \cdot 1$ & $19 \cdot 4$ & $9 \cdot 8$ \\
\hline Polyunsaturated (g) & $10 \cdot 6$ & $7 \cdot 4$ & 9.9 & $6 \cdot 7$ & $7 \cdot 4$ & 3.7 & $7 \cdot 8$ & 5.9 \\
\hline Cholesterol (mg) & $325 \cdot 6$ & $168 \cdot 8$ & 331.9 & $189 \cdot 8$ & $268 \cdot 2$ & 151.5 & $268 \cdot 5$ & $172 \cdot 3$ \\
\hline Fibre $(g)$ & $21 \cdot 3^{*}$ & 9.2 & $19 \cdot 2$ & $7 \cdot 8$ & $14 \cdot 3$ & $7 \cdot 1$ & $15 \cdot 7$ & $7 \cdot 3$ \\
\hline Alcohol (g) & $19 \cdot 5$ & $19 \cdot 9$ & $21 \cdot 8$ & $20 \cdot 1$ & $4 \cdot 1^{*}$ & $6 \cdot 7$ & $7 \cdot 5$ & $10 \cdot 5$ \\
\hline
\end{tabular}

Mean values were significantly different from those of the non-diabetic subjects for each sex (linear regression models adjusted for age and educational level): ${ }^{\star} P<0.05$; ${ }^{\star \star} P<0.01 ;{ }^{* \star \star} P<0.001$. 
criteria were combined, only one diabetic subject was totally in compliance with the nutritional recommendations. In addition, regarding the American and European recommendations, $77.2 \%$ of the diabetic subjects consumed less than $60 \%$ of daily energy intake as carbohydrates and monounsaturated fats.

\section{Discussion}

The present study on the food habits of elderly subjects showed that food behaviour differed between diabetic and non-diabetic subjects, particularly with a lower intake of carbohydrates, essentially due to a lower intake of monoand disaccharides. However, food behaviours of diabetic subjects did not seem to be appropriate since consumption of carbohydrates was too low in these elderly diabetic subjects and about two-thirds of them were not in line with the recommendations and consumed less than $45 \%$ of daily energy intake as carbohydrates. Moreover, protein intake was high in diabetic men.

Compared to nutritional recommendations, total energy intake appears to be relatively low in the present results, particularly among women. However, total energy intake reported in the present study was similar ${ }^{11,23,24}$ or only slightly lower ${ }^{8,12,13,25}$ compared to previous evaluations in diabetic subjects or healthy elderly. When lower, these differences could be partly explained by the fact that our population was older. Although the present results were comparable to previous ones, under-reporting of intake cannot totally be ruled out. Indeed, in the present population, although total energy intake appears to be relatively low, BMI is high among diabetic subjects. Even if nutritional assessment was performed in the same way in diabetic and non-diabetic subjects and was part of an epidemiological study whose primary objective was not nutrition, a selective under-reporting of restricted foods among diabetic subjects cannot be ruled out. However, previous studies with similar reports of energy intake consistently found a high BMI among diabetic subjects $8,9,11-13$.

The present results were based only on one $24 \mathrm{~h}$ recall of food consumption. Thus, for an individual, it does not reflect his/her regular food habits, since diet varies from day to day. However, it represents mean values for the groups of diabetic and non-diabetic subjects ${ }^{26}$. One limitation in this method is that the within-person variation is such that the median tends to be correct, but the variance is increased ${ }^{27,28}$. In the present study, the $24 \mathrm{~h}$ recall was assessed using food photographs which generally have a positive influence on the relative validity for absolute food group intake ${ }^{29}$. In addition, although validity has not been evaluated for each nutrient, dietary assessment methods have been previously validated for fat intake ${ }^{18,30}$ and the mean energy intake was positively associated with the intensity of physical activity in the present study $^{18}$.

Nevertheless, the present results are very close to previous results in a younger French population ${ }^{13}$. This replication of results, in a similar population but of different age, limits the risk of methodological bias. For many diabetic subjects in the present population, nutritional behaviour appears to be different to the French nutritional recommendations for diabetic persons. Indeed, many diabetic subjects in the present 
population consumed fewer carbohydrates than recommended. Yet, this population has a modified diet compared to the non-diabetic population. The decrease of mono-/disaccharide consumption, of alcohol consumption for women and the increase of artificial sweetener consumption bear witness to these modifications, but they seem partly inadequate. This is probably due to the fact that the current belief for diabetes is that people need to avoid sugar and many diabetic people are not aware of the necessity of high carbohydrate consumption and an adequate carbohydrate/lipid ratio. Thus, nutritional information should clearly underline the main messages.

In France, dietary recommendations directed towards subjects with type 2 diabetes do not specifically include the consumption of monounsaturated fats, except for subjects with abdominal obesity, hypertriglycaeridemy, and low HDLcholesterol $^{20}$. These cases apart, the main recommendation is that carbohydrates should provide about half the total energy intake ${ }^{21}$. When considering this recommendation, only one-third of the diabetic subjects consumed enough carbohydrates. Moreover, because of increased within-person variation due to use of the $24 \mathrm{~h}$ recall, the actual percentage of people who habitually eat less than $45 \%$ of energy from carbohydrates is probably greater than the estimated value. The proportion of subjects in line with nutritional recommendations has rarely been provided directly in previous published data. Even if results cannot be compared directly since recommendations differ across countries, the present result appear to be in contradiction with previous data in a Spanish population, where more than $80 \%$ of the patients complied with the recommendation of consuming more than $60 \%$ of daily energy intake as carbohydrates and monounsaturated fats $^{12}$. However, consumption of carbohydrates was relatively low in this Spanish population, about $38 \%$ of total energy; the high compliance with recommendations was explained by a very high consumption of fats (almost $40 \%$, including about $56 \%$ of monounsaturated fats), which appears to be a common nutritional habit in Spain rather than respect of nutritional recommendations in this diabetic population. In other studies, the mean consumption of carbohydrates and monounsaturated fats was lower than $60 \%$ in two of the three countries in the Seven Countries Study ${ }^{11}$ and also in France ${ }^{13}$.

The low intake of carbohydrates in the present diabetic population leads to an imbalance between carbohydrates and lipids, which hampers the action of insulin. Thus, this nutritional behaviour of reducing carbohydrate intake is deleterious for the management of these diabetic patients, making it more difficult to obtain glycaemic control and probably increasing the vascular risk associated with diabetes.

Beyond the low intake of carbohydrates in the present diabetic population, the difference between diabetic men and women in nutritional behaviour is of particular interest. Indeed, diabetic women decrease their nutritional intake whereas diabetic men increase their protein consumption. Both of these are risk behaviours. The decrease in energy intake can lead to malnutrition in women. Thus, although high BMI is problematic, nutritional recommendations for this population should be cautious and not too restrictive. In men, the high intake of protein constitutes a risk for renal function, particularly in the case of nephropathy, which may be frequent in this population.
For non-diabetics, in comparison with the French recommendations for the elderly, protein intake was slightly higher and mean carbohydrate intake was lower. However, despite a mean increase of protein intake, a previous paper on the same population evidenced that $44 \%$ of the elderly consumed lower than $1 \mathrm{~g}$ protein/ $\mathrm{kg}$ per $\mathrm{d}$, suggesting that some protein-energy malnutrition occurs in the elderly, putting them at higher risk of sarcopaenia ${ }^{18}$. Despite an adequate intake of total fat, non-diabetics had an excessive intake of saturated fat compared to the current French recommendations, concomitant to a low monounsaturated fat intake. This latter result confirms that the French diet is not perfect despite a relatively low incidence of heart diseases.

The present results offer several clues on how to improve nutritional recommendations for the elderly population. Although the diet of diabetic subjects differs from that of non-diabetic subjects, it is not totally in line with nutritional recommendations. The message is probably poorly understood or distorted. Thus, nutritional advice should focus on the main messages such as the need for a large quantity of carbohydrates and moderate protein consumption, as well as the need to avoid malnutrition in the diabetic population.

\section{Acknowledgements}

The 3C Study is conducted under a partnership agreement between the Institut National de la Santé et de la Recherche Médicale (INSERM), Victor Segalen Bordeaux 2 University and the Sanofi-Synthélabo Company. The Fondation pour la Recherche Médicale funded the preparation and initiation of the study. The 3C Study is also supported by the Caisse Nationale Maladie des Travailleurs Salariés, Agence Française de Sécurité Sanitaire des Produits de Santé, Direction Générale de la Santé, Conseils Régionaux of Aquitaine and Bourgogne, Fondation de France, Ministry of Research-INSERM Programme 'Cohortes et collections de données biologiques'. The present study was supported by a grant from the Association Internationale pour la Recherche sur la Maladie d'Alzheimer (AIRMA).

\section{References}

1. Papazoglou N, Manes C, Chatzimitrofanous P, Papadeli E, Tzounas K, Scaragas G, Kontogiannis I \& Alexiades D (1995) Epidemiology of diabetes mellitus in the elderly in northern Greece: a population study. Diabet Med 12, 397-400.

2. Bourdel-Marchasson I, Dubroca B, Manciet G, Decamps A, Emeriau JP \& Dartigues JF (1997) Prevalence of diabetes and effect on quality of life in older French living in the community: the PAQUID Epidemiological Survey. J Am Geriatr Soc $\mathbf{4 5}$ 295-301.

3. Rockwood K, Tan M, Phillips S \& McDowell I (1998) Prevalence of diabetes mellitus in elderly people in Canada: report from the Canadian Study of Health and Aging. Age Ageing 27, 573-577.

4. Castell C, Tresserras R, Serra J, Goday A, Lloveras G \& Salleras L (1999) Prevalence of diabetes in Catalonia (Spain): an oral glucose tolerance test-based population study. Diabetes Res Clin Pract 43, 33-40.

5. Stratton IM, Adler AI, Neil HA, Matthews DR, Manley SE, Cull CA, Hadden D, Turner RC \& Holman RR (2000) Association of glycaemia with macrovascular and microvascular complications 
of type 2 diabetes (UKPDS 35): prospective observational study. Br Med J 321, 405-412.

6. American Diabetes Association (2002) Standards of medical care for patients with diabetes mellitus. Diabetes Care 25, Suppl. 1, S33-S49.

7. Hippisley-Cox J \& Pringle M (2004) Prevalence, care, and outcomes for patients with diet-controlled diabetes in general practice: cross sectional survey. Lancet 364, 423-428.

8. Shimakawa T, Herrera-Acena MG, Colditz GA, Manson JE, Stampfer MJ, Willett WC \& Stamper MJ (1993) Comparison of diets of diabetic and nondiabetic women. Diabetes Care 16, 1356-1362.

9. Parker DR, McPhillips JB, Lapane KL, Lasater TM \& Carleton RA (1995) Nutrition and health practices of diabetic and nondiabetic men and women from two southeastern New England communities. Nutr Health 10, 255-268.

10. Toeller M, Klischan A, Heitkamp G, Schumacher W, Milne R, Buyken A, Karamanos B \& Gries FA (1996) Nutritional intake of 2868 IDDM patients from 30 centres in Europe. EURODIAB IDDM Complications Study Group. Diabetologia 39, 929-939.

11. Virtanen SM, Feskens EJ, Rasanen L, Fidanza F, Tuomilehto J, Giampaoli S, Nissinen A \& Kromhout D (2000) Comparison of diets of diabetic and non-diabetic elderly men in Finland, The Netherlands and Italy. Eur J Clin Nutr 54, 181-186.

12. Cruz AF \& Calle-Pascual AL (2004) Diabetes Nutrition and Complications Trial: trends in nutritional pattern between 1993 and 2000 and targets of diabetes treatment in a sample of Spanish people with diabetes. Diabetes Care 27, 984-987.

13. Gauthier-Chelle K, Mennen L, Arnault N, Rigalleau V, Hercberg S \& Gin H (2004) Comparison of the diet of self-declared diabetics with non-diabetic patients in the SU.VI.MAX study: did the diabetics modify their nutritional behavior? Diabetes Metab 30, 535-542.

14. 3C Study Group (2003) Vascular factors and risk of dementia: design of the Three-City Study and baseline characteristics of the study population. Neuroepidemiology 22, 316-325.

15. Hercberg S, Preziosi P, Briancon S, Galan P, Triol I, Malvy D, Roussel AM \& Favier A (1998) A primary prevention trial using nutritional doses of antioxidant vitamins and minerals in cardiovascular diseases and cancers in a general population: the SU.VI.MAX study - design, methods, and participant characteristics. SUpplementation en VItamines et Mineraux AntioXydants. Control Clin Trials 19, 336-351.

16. SU.VI.MAX (2000) Portions alimentaires. Manuel photos pour l'estimation des quantités. Paris: Diffusion Economica.

17. Favier J, Ireland-Ripert J, Toque C \& Feinberg M (1995) Répertoire général des aliments. Table de composition. Paris: Editions Tec et Doc Lavoisier et INRA éditions.

18. Feart C, Jutand MA, Larrieu S, Letenneur L, Delcourt C, Combe N \& Barberger-Gateau P (2007) Energy, macronutrient and fatty acid intake of French elderly community dwellers and association with socio-demographic characteristics: data from the Bordeaux sample of the Three-City Study. Br J Nutr Published online 29 May 2007.

19. Alberti KG \& Zimmet PZ (1998) Definition, diagnosis and classification of diabetes mellitus and its complications. Part 1 : diagnosis and classification of diabetes mellitus provisional report of a WHO consultation. Diabet Med 15, 539-553.

20. ANAES: Agence Nationale d'Accréditation et d'Evaluation en Santé (2000) Stratégie de prise en charge du patient diabétique de type 2 à l'exclusion de la prise en charge des complications. Recommandations pour la pratique clinique. http://www.anaes. fr/anaes/anaesparametrage.nsf.

21. The Diabetes and Nutrition Study Group (DNSG) of the European Association for the Study of Diabetes (EASD) (2000) Recommendations for the nutritional management of patients with diabetes mellitus. Eur J Clin Nutr 54, 353-355.

22. American Diabetes Association (2002) Evidence-based nutrition principles and recommendations for the treatment and prevention of diabetes and related complications. Diabetes Care 25, Suppl. 1, S50-S60.

23. Koehler KM, Hunt WC \& Garry PJ (1992) Meat, poultry, and fish consumption and nutrient intake in the healthy elderly. J Am Diet Assoc 92, 325-330.

24. Bamia C, Orfanos P, Ferrari P, et al. (2005) Dietary patterns among older Europeans: the EPIC-Elderly study. $\mathrm{Br} J$ Nutr 94, 100-113.

25. Haveman-Nies A, Tucker KL, de Groot LC, Wilson PW \& van Staveren WA (2001) Evaluation of dietary quality in relationship to nutritional and lifestyle factors in elderly people of the US Framingham Heart Study and the European SENECA study. Eur J Clin Nutr 55, 870-880.

26. Willett W (1998) 24-Hour dietary recall and food record methods. In Nutritional Epidemiology, 2nd ed. pp. 50-73 [W Willett, editor]. Oxford: Oxford University Press.

27. Beaton GH, Milner J, Corey P, et al. (1979) Sources of variance in 24-hour dietary recall data: implications for nutrition study design and interpretation. Am J Clin Nutr 32, 2546-2559.

28. Beaton GH, Milner J, McGuire V, Feather TE \& Little JA (1983) Source of variance in 24-hour dietary recall data: implications for nutrition study design and interpretation. Carbohydrate sources, vitamins, and minerals. Am J Clin Nutr 37, 986-995.

29. Fraser GE (2003) A search for truth in dietary epidemiology. Am J Clin Nutr 78, 521S-525S.

30. Willett W, Stampfer M, Chu NF, Spiegelman D, Holmes M \& Rimm E (2001) Assessment of questionnaire validity for measuring total fat intake using plasma lipid levels as criteria. Am J Epidemiol 154, 1107-1112. 